\title{
Combination therapy with triamcinolone acetonide and bevacizumab for the treatment of severe radiation maculopathy in patients with posterior uveal melanoma
}

\author{
This article was published in the following Dove Press journal: \\ Clinical Ophthalmology \\ 19 September 2013 \\ Number of times this article has been viewed
}

\author{
Nisha V Shah' \\ Samuel K Houston' \\ Arnold Markoe ${ }^{2}$ \\ Timothy G Murray 1,2,3 \\ 'Department of Ophthalmology, \\ Bascom Palmer Eye Institute, \\ University of Miami Miller School \\ of Medicine, Miami, FL, USA; \\ ${ }^{2}$ Department of Radiation Oncology, \\ University of Miami Miller School of \\ Medicine, Miami, FL, USA; ${ }^{3}$ Murray \\ Ocular Oncology and Retina, \\ Miami, FL, USA
}

Purpose: To evaluate the role of intravitreal triamcinolone acetonide in patients who developed severe, visually compromising radiation maculopathy or progressed despite anti-angiogenic treatments.

Methods: An Institutional Review Board approved, consecutive, retrospective study from 2006 to 2009 of patients who developed severe, visually compromising radiation retinopathy manifesting as macular edema secondary to iodine-125 plaque brachytherapy for posterior uveal melanoma, were treated with a combination of intravitreal bevacizumab and intravitreal triamcinolone. Patients were evaluated with spectral domain optical coherence tomography (SD-OCT) at 2-4 month intervals following plaque removal. Treatment with intravitreal bevacizumab commenced at the first signs of visually compromising macular edema diagnosed with SD-OCT. Triamcinolone acetonide was administered to patients with severe maculopathy as consolidative therapy, or for patients that were refractory to repeated bevacizumab injections with persistent or worsening cystoid macular edema and lack of improvement or progressive worsening of best corrected visual acuity (BCVA).

Results: Twenty-five patients were evaluated after receiving a combination of intravitreal bevacizumab and triamcinolone. Initial treatment commenced at a mean of 14.5 (range of 2-42) months after plaque brachytherapy. Patients were given a mean of two injections (range 1-6) of triamcinolone acetonide, and a mean of 8.8 bevacizumab injections (range of 1-26) with a mean follow-up of 31.2 months. Radiation maculopathy upon first detection had a mean SD-OCT grade of 3.6 (median $=4)$, with an associated mean entry level BCVA of 20/70. Visual acuity at time of first intravitreal triamcinolone was 20/138. At last follow-up (mean of 45.5 months after plaque brachytherapy) mean BCVA was 20/136; however, 9 of 25 (36\%) patients who presented with severe radiation maculopathy demonstrated 20/50 or better vision at last follow-up.

Conclusion: This case series suggests a beneficial role for intravitreal triamcinolone as a consolidation treatment for patients who present with severe radiation maculopathy or as an adjuvant to bevacizumab for refractory or progressive maculopathy.

Keywords: triamcinolone acetonide, bevacizumab, radiation maculopathy, uveal melanoma

\section{Introduction}

Optical coherence tomography (OCT) classification of macular edema is gaining popularity for the detection and monitoring of radiation induced macular edema, which can be graded on a 1-5 scale that was first introduced by Horgan et al. ${ }^{1}$ This edema grading scale has also been shown to correlate with foveal thickness and visual acuity (personal communication, 2008). Based on our experience with radiation macular edema, we have extended this grading system to include grade 6 radiation maculopathy associated 
with severe foveal cystoid macular edema and subretinal fluid. Recent findings utilizing spectral domain optical coherence tomography (SD-OCT) have demonstrated that these earliest signs of radiation maculopathy manifest as macular edema, ${ }^{2}$ with average onset of OCT-evident edema by 12 months. In addition, SD-OCT can detect macular edema up to 5 months earlier than clinically detectable radiation maculopathy, with macular edema evident as early as 4 months after radiation treatment. ${ }^{3-6}$ The potential reversibility of macular edema ${ }^{4}$ serves as a target for therapeutic intervention, particularly since the presence of macular edema reflects a worse prognosis in patients developing radiation maculopathy. ${ }^{7}$ In addition, studies have shown that chronic, massive cystoid macular edema may lead to disruption of the photoreceptor inner segment/outer segment junction, a finding that has been correlated with decreased visual acuity. ${ }^{8-10}$ Thus, even with resolution of edema and restoration of normal retinal architecture, patients often fail to regain prior vision. At the Bascom Palmer Eye Institute, we often utilize triamcinolone acetonide as a combination treatment with intravitreal bevacizumab in patients with severe, massive macular edema and cystic changes where bevacizumab does not lead to significant improvement. In these patients, combination treatment with bevacizumab followed by consolidation with supplemental triamcinolone may stabilize macular edema and preserve visual acuity.

\section{Methods}

\section{Patients}

The University of Miami Institutional Review Board approved this retrospective study. Inclusion criteria included patients who developed radiation maculopathy after undergoing treatment with iodine-125 (I-125) plaque brachytherapy for uveal melanoma from 2006 to 2009, who were followed up for a minimum of 6 months, and who were treated with both triamcinolone acetonide and bevacizumab intravitreal injections for radiation macular edema. Patients were evaluated with SD-OCT (Spectralis, Heidelberg Engineering, Heidelberg, Germany) using a 5-line raster protocol at 2-4 month intervals following plaque removal with follow-up at 1-2 month intervals upon diagnosis and treatment of macular edema. Best corrected visual acuity (BCVA) was collected with Snellen charts, but visual acuity was converted to logarithm of minimum angle of resolution (logMAR) to calculate mean BCVA.

\section{Plaque brachytherapy procedure}

All patients presenting with posterior uveal melanoma underwent I-125 radioactive plaques using standard surgi- cal techniques. ${ }^{11-13}$ Briefly, after initial prepping, draping, and anesthesia, patients underwent 360 degree conjunctival peritomy. All four rectus muscles were isolated using 2-0 Ethibond sutures, and the globe was transilluminated to mark the tumor's location. If needed, one of the rectus muscles was disinserted to make room for plaque insertion. A standard Collaborative Ocular Melanoma Study plaque (a silastic implant including integrated I-125 seed grooves placed into a gold backed shield) with I-125 plaque seeds designed to deliver 85 Gy to the tumor apex was used in all cases. After the plaque was brought into the field, 5-0 nylon sutures were used to place the plaque, and the position was tested with intraoperative ultrasound by either the surgeon (TGM) or a registered diagnostic medical ultrasonographer using a contact B-scan instrument (Ophthascan S; Alcon Surgical, Inc, Irvine, CA, USA or Innovative Imaging, Inc, Sacramento, CA, USA). Echographic studies were performed to acquire both longitudinal and transverse plaque views relative to the tumor. ${ }^{14-16}$ Photographic documentation and hard copy records were obtained. If removed, the rectus muscle was reattached, and the conjunctiva was closed. The operative eye was patched and shielded with a lead shield, and the plaque was removed after a mean of 3 days and 3 hours (range 3-4 days).

\section{Intravitreal bevacizumab/triamcinolone acetonide injections}

Patients were evaluated with SD-OCT at 2-4 month intervals following plaque removal, along with complete ophthalmic examination including indirect ophthalmoscopy, echography, and wide field imaging. Once macular edema was identified, patients received follow-up at 1-2 months as needed with the schedule based on macular edema response to treatment. Radiation maculopathy was graded in the following fashion: grade 1 indicates extrafoveal, noncystoid edema; grade 2 , extrafoveal cystoid edema; grade 3, foveal noncystoid edema; grade 4, mild to moderate foveal cystoid edema; grade 5 , severe foveal cystoid edema; ${ }^{1}$ and grade 6 indicates severe foveal cystoid edema with subretinal fluid. Treatment with intravitreal bevacizumab $1.25 \mathrm{mg} / 0.05 \mathrm{cc}$ (prepared by Bascom Palmer Eye Institute compounding pharmacy per pharmacy protocol) commenced at the first signs of radiation maculopathy as detected by SD-OCT evidence of macular edema associated with a decline in BCVA worse than 20/20. ${ }^{1}$ The need for repeat injections for recurrent or persistent radiation maculopathy was associated with a lack of improvement or decline in BCVA and/or continued macular edema on SD-OCT. Cases with severe radiation maculopathy or cases refractory to bevacizumab monotherapy were given 
intravitreal injection with triamcinolone acetonide $4 \mathrm{mg} / 0.1 \mathrm{cc}$ (utilized preservative free preparation). Severe radiation maculopathy was defined as grade 5 or grade 6 edema as based on SD-OCT grading. Cases defined as refractory were patients who received at least three intravitreal bevacizumab injections with minimal improvement in macular edema.

\section{Results}

Out of our larger series of patients who developed radiation maculopathy following plaque brachytherapy for uveal melanoma, 13\% (25 of 186) of patients underwent combination therapy with triamcinolone acetonide and bevacizumab intravitreal injections. The mean age was 61.3 years, with $48 \%$ males and $52 \%$ females (Table 1 ). Patients were treated with a mean of two triamcinolone injections (range 1-6) and a mean of 8.8 bevacizumab injections (range of 1-26) over the course of 30 months (range of 10-54 months). Mean time to development of radiation maculopathy for these particular patients was similar to that for all patients developing radiation maculopathy (mean of 14.5 months).

Tumor characteristics include: 14/25 (56\%) medium sized, 9/25 (36\%) large sized, and 2/25 (8\%) small sized. Seventeen of $25(68 \%)$ tumors were located in the choroid, $1 / 25$ (4\%) was juxtapapillary, $7 / 25(28 \%)$ were located in the ciliary body/choroid, and 4/25 (16\%) demonstrated macular involvement.

Table I Patient demographics and visual acuity at first detection of spectral domain optical coherence tomography radiation maculopathy and last follow-up visit in radiation maculopathy patients

\begin{tabular}{ll}
\hline Outcomes & Values $\mathbf{n}=\mathbf{2 5}$, [median], (range) \\
\hline Male, female & $13, \mathrm{I} 2$ \\
Mean age & $6 \mathrm{I} .3$ years (range 38-86 years) \\
Mean number of injections & $2(\mathrm{I}-6)$ triamcinolone injections \\
& $8.8(\mathrm{I}-26)$ bevacizumab injections \\
Mean time for radiation & $\mathrm{I} 4.48$ months (range 2-42 months) \\
maculopathy development & \\
Mean f/u time after radiation & 30.0 [28.5] (I0-54) \\
maculopathy & \\
Medical history & $\mathrm{II}$ (7 with HTN retinopathy) \\
HTN & 3 \\
DM & 2 \\
ARMD & 2 \\
Neovascular glaucoma & $\mathrm{n}=9$ \\
Final BCVA 20/50 or better & $(36 \%$ of patients with radiation \\
in radiation maculopathy & retinopathy were able to maintain 20/50 \\
patients & or better vision at last follow-up visit) \\
\hline
\end{tabular}

Abbreviations: HTN, hypertension; DM, diabetes mellitis; ARMD, age-related macular degeneration; BVCA, best corrected visual acuity.
Mean visual acuities in patients receiving combination therapy were similar to the entire group of radiation retinopathy patients in terms of baseline visual acuity and visual acuity at the time of radiation maculopathy diagnosis via SD-OCT. Baseline or pre-plaque brachytherapy vision was $20 / 46$ (range of $20 / 20$ to $20 / 1,000$ ), which declined to $20 / 70$ (range of 20/25 to 20/40,000) at the time of radiation maculopathy diagnosis and commencement of treatment with intravitreal bevacizumab. Median SD-OCT macular edema grade at time of maculopathy diagnosis was 4 with a mean foveal thickness of $439.75 \mu \mathrm{m}$ (median of $375 \mu \mathrm{m}$ ) (Table 2). All patients who received combination therapy demonstrated grade 3 or worse macular edema during the treatment course which indicated foveal involvement. After a mean of 23.7 months (median of 25 and range of 0-51 months) following radiation maculopathy, triamcinolone acetonide therapy was initiated, at which time mean BCVA was 20/138 (median of 20/100). At final follow-up with combination therapy over the course of 30.0 months (median of 28.5 and range of 10-54 months), mean visual acuity was maintained at 20/136 (range of 20/20 to 20/8,000), which correlated to macular edema grade 3.7 (median of 4 ) and mean foveal thickness of $426.7 \mu \mathrm{m}$ (median of $351 \mu \mathrm{m}$ and range of 209-661 $\mu \mathrm{m})$. However, 9 of 25 (36\%) patients demonstrated $20 / 50$ or better vision by last follow-up visit,

Table 2 Treatment outcome measures for patients receiving combination therapy with bevacizumab and triamcinolone acetonide compared to the entire group of radiation maculopathy patients

\begin{tabular}{|c|c|c|}
\hline Time & $\begin{array}{l}\text { Subset administered } \\
\text { combination therapy } \\
\mathrm{n}=25, \text { [median], } \\
\text { (range) }\end{array}$ & $\begin{array}{l}\text { All radiation } \\
\text { maculopathy } \\
\text { patients } n=186, \\
\text { [median], (range) }\end{array}$ \\
\hline Pre-plaque (mean) & $\begin{array}{l}20 / 46(20 / 20 \text { to } \\
20 / 1,000)\end{array}$ & $\begin{array}{l}20 / 55[20 / 40] \\
(20 / 20 \text { to } 20 / 8,000)\end{array}$ \\
\hline $\begin{array}{l}\text { At radiation } \\
\text { maculopathy } \\
\text { diagnosis }\end{array}$ & $\begin{array}{l}20 / 70(20 / 25 \text { to } \\
20 / 40,000)\end{array}$ & $\begin{array}{l}20 / 74(20 / 25 \text { to } \\
20 / 20,000)\end{array}$ \\
\hline $\begin{array}{l}\text { Pretreatment median } \\
\text { macula edema }\end{array}$ & 4 & 3 \\
\hline $\begin{array}{l}\text { Pretreatment mean } \\
\text { foveal thickness }\end{array}$ & $\begin{array}{l}439.75 \mu \mathrm{m} \\
(\text { median } 375 \mu \mathrm{m})\end{array}$ & $\begin{array}{l}347[302] \\
(124-984)\end{array}$ \\
\hline $\begin{array}{l}\text { BCVA at time } \\
\text { of first IVTA }\end{array}$ & $20 / 138$ & \\
\hline Posttreatment & $20 / 136(20 / 20$ & $20 / 120[20 / 50]$ \\
\hline BCVA & to $20 / 8,000$ ) & $\begin{array}{l}(20 / 20 \text { to } \\
20 / 200,000)\end{array}$ \\
\hline $\begin{array}{l}\text { Mean macula edema } \\
\text { posttreatment }\end{array}$ & 3.7 (median 4) & $2.4[3]$ \\
\hline $\begin{array}{l}\text { Posttreatment mean } \\
\text { foveal thickness }\end{array}$ & $\begin{array}{l}426.7[35 \mathrm{I}] \\
\text { (range 209-66I) }\end{array}$ & 354 [303] (I85-984) \\
\hline
\end{tabular}

Abbreviations: BVCA, best corrected visual acuity; IVTA, intravitreal triamcinolone acetonide. 
with the mean visual acuity being better than 20/150, representing ambulatory vision (Table 3 ).

\section{Discussion}

Triamcinolone acetonide may have direct angiostatic and anti-inflammatory effects by upregulating the extracellular matrix protein plasminogen activator inhibitor, while blocking inflammatory cytokines, specifically selectins, integrins, intercellular adhesion molecule-1, and tumor necrosis factoralpha. ${ }^{17}$ Earlier studies have shown inhibition of hypoxia induced upregulation of vascular endothelial growth factor (VEGF) by cultured retinal pigment epithelium cells, which suggests an enhancement effect when given together with anti-VEGF therapy. ${ }^{18-20}$ Our study investigates the role of intravitreal triamcinolone acetonide and anti-VEGF combination therapy for treatment of severe radiation maculopathy, and is the first case series to our knowledge utilizing this particular treatment regimen. ${ }^{21-23}$

Horgan et al presented 109 patients showing that administration of peri-ocular triamcinolone acetonide administered at the time of plaque brachytherapy and again at 4-8 months demonstrated a reduction in moderate (three or more Snellen lines) and severe $(<5 / 200)$ vision loss when compared to controls. ${ }^{22}$ The study also found no increased rates of intraocular pressure elevation in the triamcinolone group. Shields et al reported the effect of a one-time administration of intravitreal triamcinolone (4 mg/0.1 mL) in a prospective, nonrandomized, single center case series of 31 patients with visually symptomatic radiation induced macular edema after plaque radiotherapy. ${ }^{23}$ They reported that after administrating an intravitreal injection of triamcinolone acetonide at the time of clinical diagnosis, visual acuity remained stable or improved in 91\% (20 of 22) of patients by 1 month and $45 \%$ (14 of 31 ) of cases by 6 months. This decline over

Table 3 Best corrected visual acuity at last follow-up visit

\begin{tabular}{ll}
\hline BCVA $(\mathbf{n}=\mathbf{2 5})$ & Last follow-up BCVA \\
\hline $20 / 20$ or better & $3(12 \%)$ \\
$20 / 25$ to $20 / 50$ & $6(24 \%)$ \\
$20 / 60$ to $20 / 80$ & 0 \\
$20 / 100$ to $20 / 160$ & $3(12 \%)$ \\
$20 / 200$ to $20 / 320$ & $8(14.5 \%)$ \\
$20 / 400$ to $20 / 760$ & $3(12 \%)$ \\
$20 / 800$ or worse & $2(6 \%)$ \\
Enucleation & 0 \\
Total patients & 25 \\
Mean visual acuity & $20 / 136(20 / 20$ to $20 / 8,000)$ \\
\hline Abbreviation: BVCA, best corrected visual acuity.
\end{tabular}

time suggests the need for routine monitoring and potential subsequent injections of triamcinolone.

Our group has previously reported on another subset of patients who developed radiation maculopathy ${ }^{24}$ following I-125 plaque brachytherapy for uveal melanoma. Shah et al reported on 81 patients ( $50.9 \%$ of total radiation maculopathy cases) who developed visually significant radiation maculopathy and who maintained $20 / 50$ or better vision with the early institution of intravitreal bevacizumab. ${ }^{24}$ The study emphasized the importance of close serial monitoring of the macula with SD-OCT to ensure early identification of retinal changes, thus allowing for early and targeted treatment with anti-VEGF agents. The current study examines a subset of those patients who developed severe maculopathy or maculopathy that was refractory to anti-VEGF monotherapy.

Despite visually significant changes from severe foveal involving macular edema, $36 \%$ of patients demonstrated $20 / 50$ or better vision at last follow-up. In addition, in this subset of advanced cases, mean visual acuity was better than 20/150, which signifies ambulatory vision. We have noted that entry level BCVA often reflects final BCVA, and poor entry level BCVA is frequently the result of chronic cystic changes that are refractory to treatment with anti-VEGF alone (Figures 1 and 2). Additionally, despite improvement in macular edema, often there are permanent inner segment ellipsoid band (previously inner segment/outer segment junction) changes that are associated with poor visual potential. For severe cases or edema that is refractory to anti-VEGF monotherapy, alternative and adjuvant treatment with triamcinolone acetate may offer significant benefit to these patients.

While it has been suggested that intravitreal injections of triamcinolone acetonide may be associated with side effects, including glaucoma, cataracts, retinal detachment, and endophthalmitis, ${ }^{25,26}$ no patients in our series developed endophthalmitis or underwent enucleation. ${ }^{27}$ Cataract formation is common following plaque brachytherapy, and the use of intravitreal triamcinolone may have an additive effect. ${ }^{28}$ We have previously reported on the use of triamcinolone acetonide following pars plana vitrectomy to decrease the incidence of cystoid macular edema. ${ }^{29}$ Intraocular pressure elevation was rarely seen after postoperative day 1 , with an incidence of $7.7 \%-9 \%$, with 5\% requiring intraocular pressure lowering medications. Limitations to the current study include the small sample size and its retrospective nature.

In conclusion, the current study has shown that patients with severe, massive cystic edema that is often refractory to anti-VEGF agents, may benefit from consolidative therapy 


\section{Patients treated with triamcinolone and bevacizumab combination $(n=25)$}

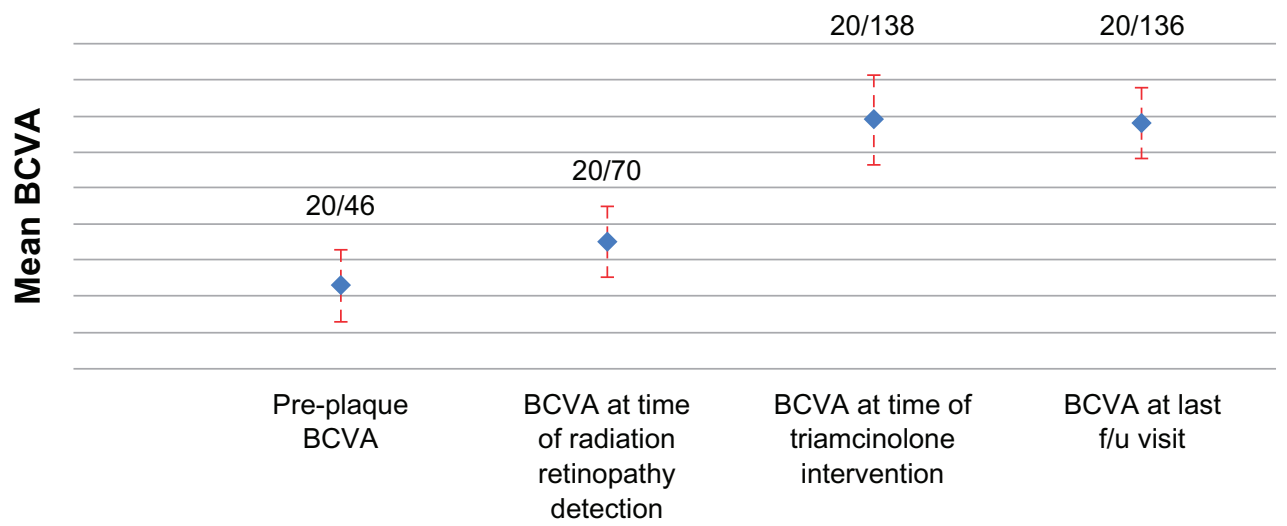

Figure I Mean best corrected visual acuity for patients receiving triamcinolone and bevacizumab combination treatment $(\mathrm{n}=25)$ at the time of plaque brachytherapy treatment, time of detection of spectral domain optical coherence tomography macular edema, time at first intervention with triamcinolone, and at last follow-up visit. Notes: Twenty-five patients were given a mean of two injections (range I-6) of triamcinolone acetonide and mean of 8.9 bevacizumab injections (range of I-26) over a mean of 31.2 months, starting at time of spectral domain optical coherence tomography diagnosis of radiation maculopathy, which occurred I4.5 (range of 2-42) months after plaque brachytherapy.

Abbreviation: BCVA, best corrected visual acuity; f/u, follow-up.

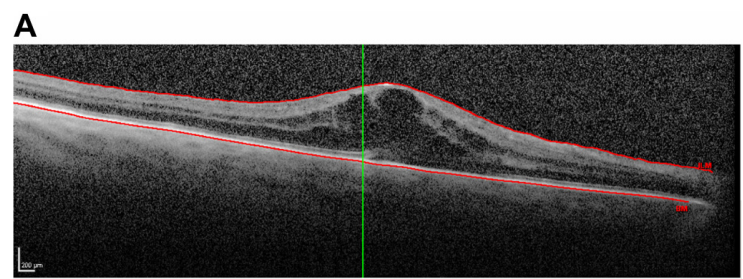

$\mathbf{B}$

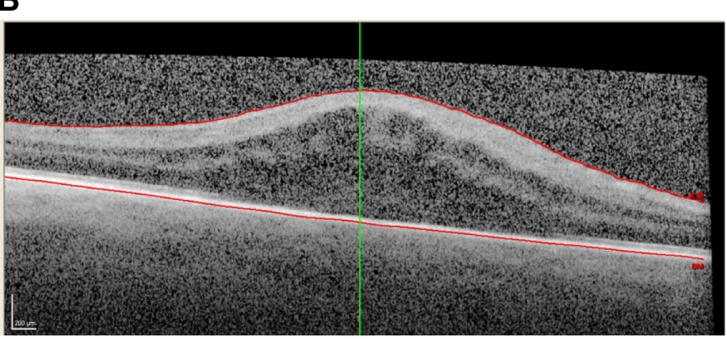

C

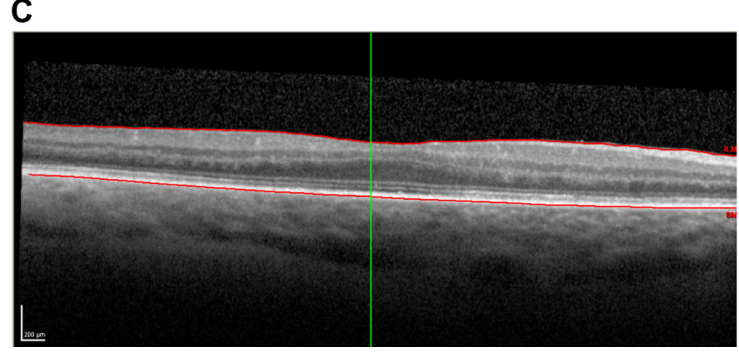

Figure 2 Images of plaque brachytherapy.

Notes: This patient underwent plaque brachytherapy OD (right eye), in which the patient had 20/70 vision. Nine months later, the patient is diagnosed with grade 5 macular edema via spectral domain optical coherence tomography and was given the first injection of bevacizumab. Vision at this time is 20/400 with mean foveal thickness of $600 \mu \mathrm{m}$ (A). Five months after presentation of radiation retinopathy, radiation maculopathy persisted at grade 5 macular edema with mean foveal thickness of $698 \mu \mathrm{m}$ (B) and the patient was given intravitreal triamcinolone therapy. Vision at this time was 20/200. At the last follow-up visit 21 months after plaque treatment, macular edema resolved with mean foveal thickness of $302 \mu \mathrm{m}$, and best corrected visual acuity improved to $20 / 40$ (C). with triamcinolone acetonide. Using combination treatment, more than a third of patients maintained 20/50 or better vision, with the majority of patients maintaining ambulatory vision. However, there appears to be a group of patients who despite improvement in intraretinal fluid, fail to improve vision.

\section{Disclosure}

The authors report no conflict of interest in this work.

\section{References}

1. Horgan N, Shields CL, Mashayekhi A, Teixeira LF, Materin MA, Shields JA. Early macular morphological changes following plaque radiotherapy for uveal melanoma. Retina. 2008;28:263-273.

2. Levitz LM. The use of optical coherence tomography to determine the severity of radiation retinopathy. Ophthalmic Surg Lasers Imaging. 2005;36:410-411.

3. Coker JG, Duker JS. Macular disease and optical coherence tomography. Curr Opin Ophthalmol. 1996;7:33-38.

4. Mukai SGD, Gragoudal ES. Radiation retinopathy. In: Albert DM JF, editor. Principles and Practice of Ophthalmology. Vol 2. Philadelphia: WB Saunders Co; 1994:1038-1041.

5. Guyer DR, Mukai S, Egan KM, Seddon JM, Walsh SM, Gragoudas ES Radiation maculopathy after proton beam irradiation for choroidal melanoma. Ophthalmology. 1992;99:1278-1285.

6. Horgan N, Shields C, Mashayekhi, Shields JA. Classification and treatment of radiation maculopathy. Curr Opin Ophthalmol. 2010; 21:233-238.

7. Kinyoun JL. Long term visual acuity results of treated and untreated radiation retinopathy (an AOS thesis). Trans Am Ophthalmol Soc. 2008; 106:325-335.

8. Sergouniotis PI, Holder GE, Robson AG, Michaelides M, Webster AR, Moore AT. High-resolution optical coherence tomography imaging in KCNV2 retinopathy. Br J Opthalmol. 2012;96(2):213-217.

9. Gella L, Raman R, Pal SS, Nittala MG, Sharma T. Morphological and functional changes in spectral domain optical coherence tomography and microperimetry in macular microhole variants. Indian J Ophthalmol. 2012;60(1):53-56. 
10. Piña Y, Cebulla CM, Murray TG, et al. Blood vessel maturation in human uveal melanoma: spatial distribution of neovessels and mature vasculature. Ophthalmic Res. 2009;41(3):160-169.

11. Char DH. Clinical Ocular Oncology 2nd edition. Hagerstown, MD, Lippincott-Raven, 1997.

12. Shields JA, Shields CL, editors. Intraocular Tumors. A Text and Atlas. Philadelphia: WB Saunders Co; 1992:25-43.

13. Hui JI, Murray TG. Radioactive plaque therapy. Int Ophthalmol Clin. 2006;46(1):51-68.

14. Shah NV, Houston SK, Murray TG, Markoe AM. Evaluation of the surgical learning curve for I-125 episcleral plaque placement for the treatment of posterior uveal melanoma: a two decade review. Clin Ophthalmol. 2012;6:447-452.

15. Harbour JW, Murray TG, Byrne SF, et al. Intraoperative echographic localization of iodine 125 episcleral radioactive plaques for posterior uveal melanoma. Retina. 1996;16(2):129-134.

16. Tabandeh H, Chaudhry NA, Murray TG, et al. Intraoperative echographic localization of iodine-125 episcleral plaque for brachytherapy of choroidal melanoma. Am J Ophthalmol. 2000;129(2):199-204.

17. Nakano T, Ohara O, Teraoka H, Arita H. Glucocorticoids suppress group II phospholipase A2 production by blocking mRNA synthesis and post-transcriptional expression. J Biol Chem. 1990;265: $12745-12748$

18. Matsuda S, Gomi F, Oshima Y, Tohyama M, Tano Y. Vascular endothelial growth factor reduced and connective tissue growth factor induced by triamcinolone in ARPE19 cells under oxidative stress. Invest Ophthalmol Vis Sci. 2005;46:1062-1068.

19. Tano Y, Chandler D, Machemer R. Treatment of intraocular proliferation with intravitreal injection of triamcinolone acetonide. Am JOphthalmol. 1980;90:810-816.

20. Jonas JB, Kreissig I, Degenring R. Intravitreal triamcinolone acetonide for treatment of intraocular proliferative, exudative, and neovascular diseases. Prog Retin Eye Res. 2005;24(5):587-611.
21. Sutter FK, Gillies MC. Intravitreal triamcinolone for radiation macular edema. Arch Ophthalmol. 2003;121:1491-1493.

22. Horgan N, Shields CL, Mashayekhi A, et al. Periocular triamcinolone for prevention of macular edema after plaque radiotherapy of uveal melanoma: A randomized controlled trial. Ophthalmology. 2009; 116:1383-1390.

23. Shields CL, Demirci H, Dai V, et al. Intravitreal triamcinolone acetonide for radiation maculopathy after plaque radiotherapy for choroidal melanoma. Retina. 2005;25:868-874.

24. Shah NV, Houston SK, Markoe AM, Feuer W, Murray TG. Early SDOCT diagnosis followed by prompt treatment of radiation maculopathy using intravitreal bevacizumab maintains functional visual acuity. Clin Ophthalmol. 2012;6:1739-1748.

25. Gillies MC, Sutter FK, Simpson JM, Larsson J, Ali H, Zhu M. Intravitreal triamcinolone for refractory diabetic macular edema: Two-year results of a double-masked, placebo-controlled, randomized clinical trial. Ophthalmology. 2006;113:1533-1538.

26. Conti SM, Kertes PJ. The use of intravitreal corticosteroids, evidencebased and otherwise. Curr Opin Ophthalmol. 2006;17:235-244.

27. Cavalcante LL, Cavalcante ML, Murray TG, et al. Intravitreal injection analysis at the Bascom Palmer Eye Institute: evaluation of clinical indications for the treatment and incidence rates of endophthalmitis. Clin Ophthalmol. 2010;4:519-524.

28. Cebulla CM, Alegret AM, Feuer WJ, Shi W, Schefler AC, Murray TG. Tumor volume reduction using combined phacoemulsification and intravitreal triamcinolone injection for the management of cataract with treated uveal melanoma and atypical nevi. J Cataract Refractive Surg. 2008;23(10):1669-1673.

29. Parke DW 3rd, Sisk RA, Houston SK, Murray TG. Ocular hypertension after intravitreal triamcinolone with vitrectomy and phacoemulsification. Clin Ophthalmol. 2012;6:925-931.
Clinical Ophthalmology

\section{Publish your work in this journal}

Clinical Ophthalmology is an international, peer-reviewed journal covering all subspecialties within ophthalmology. Key topics include: Optometry; Visual science; Pharmacology and drug therapy in eye diseases; Basic Sciences; Primary and Secondary eye care; Patient Safety and Quality of Care Improvements. This journal is indexed on

\section{Dovepress}

PubMed Central and CAS, and is the official journal of The Society of Clinical Ophthalmology (SCO). The manuscript management system is completely online and includes a very quick and fair peer-review system, which is all easy to use. Visit http://www.dovepress.com/ testimonials.php to read real quotes from published authors. 